\title{
$730 \mathrm{aD} 2$
}

\author{
Defect Filtration of Hollow Pyramidal Structured GaSb Epilayers \\ Grown on GaSb (100) Patterned Substrates by Liquid Phase Epitaxy \\ 静岡大学電子工学研究所 章 国強, 小山忠信, 熊川征司, 早川泰弘 \\ Research Institute of Electronics, Shizuoka University, \\ G. Zhang, T. Koyama, M. Kumagawa, Y. Hayakawa
}

Pyramidal structured gallium antimonide epilayers with mirror-like $\{100\}$ and $\{111\}$ facets were grown on $\mathrm{GaSb}(100)$ patterned substrates by liquid phase epitaxy (LPE). The $\{111\}$ facets were identified as two different faces: (111)A and (111)B.The pyramidal structure was hollow. Due to the presence of a masking layer and hollow space, both the epitaxial lateral overgrowth (ELO) layer and the top portion of the epilayer were of high quality. This result indicated that the hollow pyramidal structure has defect filtration effect.

1. Introduction: Recently, the growth of epilayers with pyramidal structure has attracted much attention because of their potential applications. In the present investigation, a hollow pyramidal structure of $\mathrm{GaSb}$ has been grown on $\mathrm{GaSb}(100)$ patterned substrate. The resulting ELO and bridge layers were found to be of high quality.

2. Experimental method: $\mathrm{GaSb}(100)$ substrates with circular patterned open windows of diameter of $250 \mu \mathrm{m}$ were employed. A conventional LPE system was used to grow GaSb epilayers. The epilayers were analyzed using a scanning electron microscope (SEM).

3. Results and discussion: Figure 1 shows the side view of an epilayer, which contains two types of facet, namely, $\{111\}$ and $\{100\}$. Identification of the polarities of these side $\{111\}$ facets located on the surface of the pyramidal layers was achieved by etching according to their different etching patterns. It was found that that an inhomogeneous distribution of etch pits exists on both (111)A facets. However, no etch pit was found in the top portion of the epilayer, which is right above the exposed area of the substrate and expected to have dislocation. The cross sectional SEM image (fig. 2) revealed the presence of hollow space in the pyramidal structure. Fig. 3 is an illustration of defect filtration in the hollow pyramidal structure. Many dislocations propagate into the areas $Q$ and $\mathrm{S}$, but only a few dislocations reached areas $\mathrm{P}$ and $\mathrm{T}$ due to the presence of $\mathrm{SiN}_{\mathrm{x}}$ masking layer. At the same time, hollow space prevents these dislocations from propagating into the top portion of the epilayer. As a result, both the ELO layer and the top layer were of high quality.

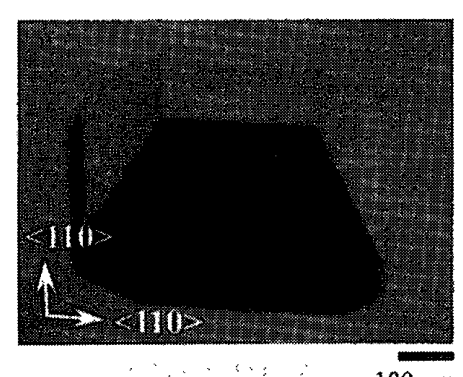

Fig.1

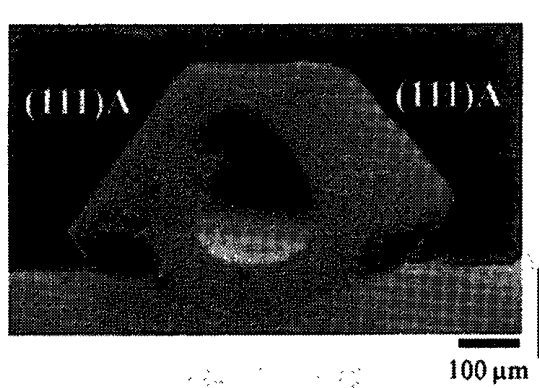

Fig.2

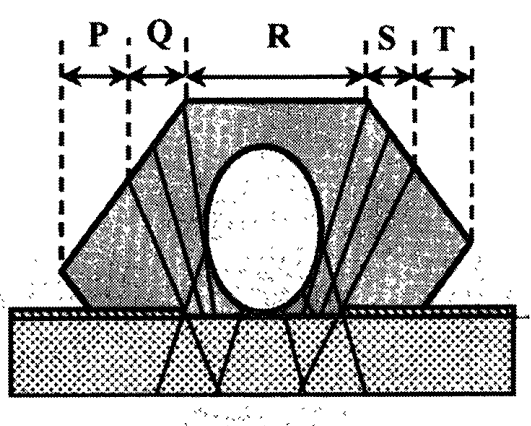

Fig. 3 